Original Research Paper

\title{
Penerapan Lubang Resapan Biopori Sebagai Upaya Peningkatan Kualitas Lingkungan di Desa Darmaji
}

\author{
Arben Virgota $^{1}$, Baiq Farista ${ }^{1}$, Rina Kurnianingsih ${ }^{2}$, Baiq Mira Permata Sari ${ }^{3}$, Ismira Anestia Iskandar ${ }^{3}$

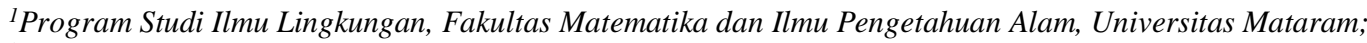 \\ ${ }^{2}$ Program Studi biologi, Fakultas Matematika dan Ilmu Pengetahuan Alam, Universitas Mataram \\ ${ }^{3}$ Teknik Sipil, Fakultas Teknik, Universitas Mataram
}

DOI: https://doi.org/10.29303/jpmpi.v4i2.816

Sitasi: Virgota, A., Farista, B., Kurnianingsih, R, Sari, B. M. P., \& Iskandar. I. A. (2021). Penerapan Lubang Resapan Biopori Sebagai Upaya Peningkatan Kualitas Lingkungan di Desa Darmaji. Jurnal Pengabdian Magister Pendidikan IPA, 4(2)

\author{
Article history \\ Received: 29 Maret 2021 \\ Revised: 20 Mei 2021 \\ Accepted: 24 Juni 2021 \\ *Corresponding Author: Arben \\ Virgota, Program Studi Ilmu \\ Lingkungan, Fakultas \\ Matematika dan Ilmu \\ Pengetahuan Alam, Universitas \\ Mataram; \\ Email: arben@unram.ac.id
}

\begin{abstract}
Darmaji Village is one of the villages on the island of Lombok which has potential in the field of food and the environment. The main problem in the environmental sector is the presence of standing water in residential areas during the rainy season and the low level of waste utilization. Efforts to overcome this are the application of bio pure infiltration holes that can act as water absorption media, increase groundwater reserves, and compost media in Darmaji village. The method of implementation is by making several pilot locations and socialization through brochures and leaflets. The results of this activity made many residents interested in applying biopori in their homes. So it is hoped that in the future it can overcome environmental problems and support tourism activities on the island of Lombok in Darmaji Village.
\end{abstract}

Keywords: Biopore Infiltration Hole; Organic Trash; Puddle; Darmaji Village.

pemukiman rumah warga. Hal ini dapat menimbulkan masalah baru, yaitu genangan air bisa menjadi sarang nyamuk dan sangat berbahaya bagi kesehatan warga sekitar. Selain karena tingginya intensitas hujan, hal ini disebabkan juga oleh berkurangnya lahan yang dapat berperan sebagai resapan air.

Disamping itu, sampah masih merupakan permasalahan yang dihadapi oleh masyarakat maupun pemerintah Desa Darmaji. Sampahsampah tersebut masih sangat rendah tingkat pemanfaatannya dalam menunjang kehidupan masyarakat sehari-hari. Sampah organik biasanya dihasilkan oleh kegiatan rumah tangga maupun pertanian. Dimana, sampah tersebut masih dianggap sebagai masalah bagi masyarakat dan menjadi beban bagi pemerintah dalam menanganinya.

masih terdapat masalah yang ada di Desa Darmaji yaitu setiap kali musim hujan tiba, lingkungan Desa Darmaji selalu terdapat genangan air di sejumlah 
Berdasarkan uraian diatas, kami merasa perlu untuk memberikan solusi agar permasalahan genangan air serta tingginya timbulan sampah dapat dikurangi. Solusi yang kami tawarkan tidak hanya diarahkan pada penyelesaian masalah genangan air dan timbulan sampah, namun kami juga berharap dapat meningkatkan manfaat sampah sebagai bahan baku produk kompos serta cadangan air tanah di Desa Darmaji.

Salah satu teknologi yang akan kami tawarkan kepada masyarakat Desa Darmaji adalah teknologi Biopori. Teknologi ini telah ditemukan oleh Insinyur Kamir R. Brata, MSc., dosen Ilmu Tanah dan Sumber Daya Lahan Institut Pertanian Bogor, Jawa Barat, sejak tahun 2000. Biopori merupakan salah satu metode yang sangat sederhana tetapi memiliki dampak yang sangat besar bagi lingkungan. Menurut Kamir (2009), lubang resapan biopori yang baru dibuat serta telah diisi sampah bisa memasukan air sebanyak 1.5 liter hingga 16 liter per menit.

Lubang resapan biopori (LRB) adalah lubang-lubang tanah yang terbentuk akibat aktivitas organisme di dalamnya, seperti cacing, perakaran tanah, rayap, dan fauna tanah lainnya. Dengan adanya aktivitas fauna tanah pada lubang resapan maka biopori akan terjaga kemampuannya dalam menyerap air dan akan terus terpelihara keberadaannya (Tim IPB, 2007).

Selain dapat meresapkan air dengan cepat, juga dapat menjaga ketersediaan cadangan air tanah dikala musim kemarau datang, serta juga dapat meminimalisir sampah organik yang berserakan dan mengolahnya menjadi kompos dengan cara memasukan media sampah-sampah organik, seperti daun, rumput, sampah rumah tangga, dan sampah lainnya ke dalam lubang biopori.

Salah satu keunggulan dari Lubang resapan biopori yaitu tidak memerlukan lahan yang luas. Untuk daerah dengan intensitas hujan tinggi dan laju resapan air sekitar 3 liter per menit, setiap 100 meter persegi luas tanah, hanya akan membutuhkan 28 lubang. Oleh karena itu, teknologi ini bisa diaplikasikan di semua jenis kawasan, termasuk kawasan yang sangat kedap air dan jika biopori itu berada diantara pepohonan, tumbuhan tersebut akan tumbuh dengan subur (Yohana et al., 2017).

Pemanfaatan pupuk kompos bukan hanya dapat diserap secara langsung untuk tanah, namun dapat diharapkan membantu masyarakat dalam menambah minat masyarakat dalam meningkatkan ketahanan pangan dengan memanfaatkan pupuk kompos untuk tanaman yang dimiliki oleh masyarakat sekitar (Griya, 2008).

\section{Metode}

Kegiatan Penerapan Lubang Resapan Biopori (LRB) dilaksanakan pada bulan Januari 2021 di Desa Darmaji, Kabupaten Lombok Tengah. Metode yang digunakan dalam kegiatan ini adalah: Pembagian brosur, leaflet dan praktek penerapan LRB di sejumlah pekarangan rumah warga sekaligus dijadikan sebagai lokasi percontohan. Pembagian brosur dan leaflet dilaksanakan untuk mensosialisasikan manfaat dan tujuan dari program penerapan LRB. Sosialisasi ini dilakukan secara langsung oleh narasumber yang kompeten di bidangnya sesuai dengan kebutuhan. Bahan yang digunakan adalah pipa PVC dengan ukuran 4 inchi dan dapat dilakukan secara mandiri maupun didampingi oleh Tim KKN. Adapun tahapan kegiatan pengabdian pada masyarakat ini adalah sebagai berikut:

1. Sosialisasi dan koordinasi dengan semua pihak terkait, kegiatan ini bertujuan untuk mengkomunikasikan rencana kegiatan serta legalisasi kegiatan.

2. Pemberian materi sosialisasi dengan menggunakan brosur dan leaflet yang berisi penjelasan mengenai penerapan LRB. Materi yang disampaikan terdiri dari pengertian umum mengenai LRB, teknik penerapan atau pembuatan LRB hingga manfaat yang akan didapat.

Diskusi dan tanya jawab yang dapat dilakukan baik itu ketika berlangsungnya penyebaran brosur dan leaflet maupun bertanya secara online.

\section{Hasil dan Pembahasan}

\section{Lokasi Percontohan}

Pembuatan Lubang Resapan Biopori (LRB) pada awalnya dilaksanakan pada 3 lokasi, yaitu di masing-masing rumah anggota Tim KKN Desa Darmaji yang juga merupakan warga Desa Darmaji. Pola ini diterapkan mengingat masih tingginya wabah covid19 di Pulau Lombok. Dengan Demikian, pola percontohan ini merupakan pilihan yang terbaik dan aman bagi masyarakat maupun anggota tim pengabdian. Lokasi percontohan 
penerapan LRB pertama dilakukan di selatan SDN 2 Darmaji kemudian lokasi percontohan yang kedua di depan TK Dahlia dan lokasi percontohan yang ketiga di depan SDN 1 Darmaji. Dua lokasi percontohan terletak di dekat jalan raya utama yaitu jalan raya Praya - Kopang sehingga memudahkan warga untuk melihat percontohan penerapan LRB dengan baik. Adapun lokasi percontohan yang ketiga merupakan rumah sekretaris Desa Darmaji sehingga diharapkan agar kedepannya seluruh warga Desa Darmaji dapat mencontoh dan menerapkannya di lahan pekarangan masingmasing.

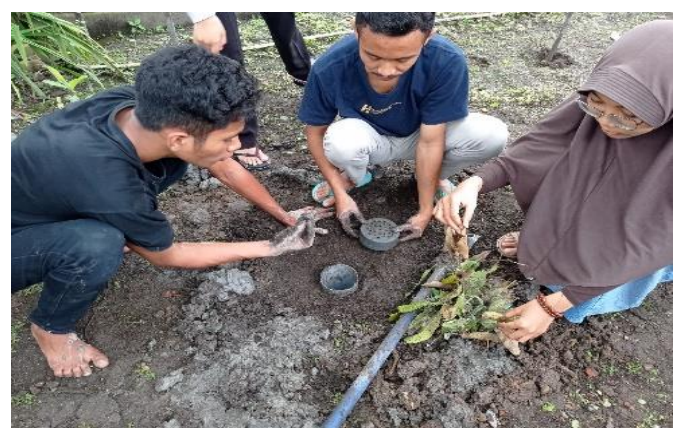

Gambar 1. Lokasi percontohan 1

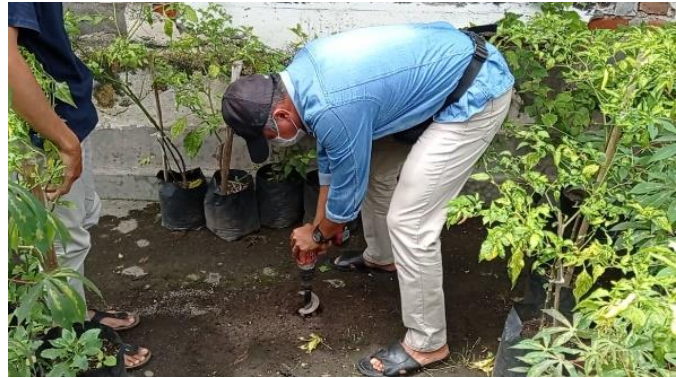

Gambar 2. Lokasi percontohan 2

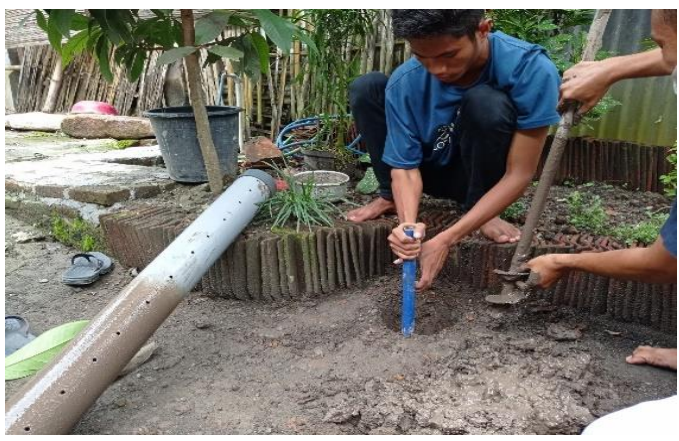

Gambar 3. Lokasi percontohan 3

\section{Kegiatan Penyuluhan}

Program Penerapan LRB meliputi penempelan leaflet dan penyebaran brosur. Penempelan leaflet dilakukan di Kantor Desa
Darmaji yang bertujuan agar semua warga Desa Darmaji dapat melihat informasi tentang program penerapan LRB. Sedangkan penyebaran brosur dilaksanakan dengan door to door ke rumah-rumah warga. Penyebaran brosur disertai dengan penjelasan langsung mengenai kegiatan program yang dilaksanakan serta manfaat yang didapatkan ketika melaksanakan program penerapan LRB.

Penerimaan masyarakat sangat baik pada program ini, dimana beberapa warga berkenan dan bersedia membuat LRB pada masing-masing lahan pekarangannya, khususnya pada bagian lahan yang sering tergenang air ketika hujan. Berdasarkan Tabel 1, dapat dilihat bahwa ada 5 (lima) warga yang telah menerapkan LRB. Pemasangan dilakukan sepenuhnya oleh warga dan dibantu oleh tim pengabdian sampai selesai. Kegiatan ini tidak hanya sampai pada tahap pemasangan LRB saja, namun juga dilakukan pengisian sampah-sampah organik yang berasal dari aktivitas rumah tangga dan lahan pekarangan.

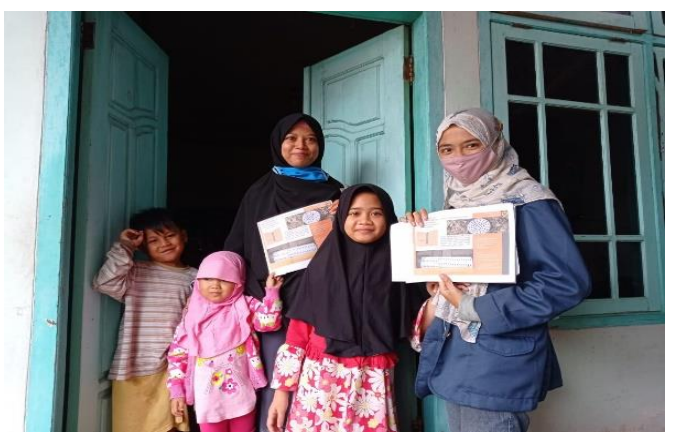

Gambar 4. Penyebaran brosur

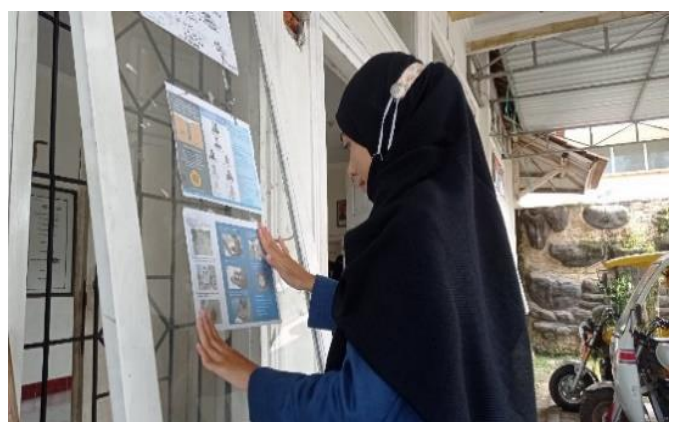

Gambar 5. Penempelan leaflet di Kantor Desa

Tabel 1. Daftar nama warga yang menerapkan program LRB.

\begin{tabular}{|c|l|l|}
\hline No & \multicolumn{1}{|c|}{ Nama } & \multicolumn{1}{c|}{ Lokasi } \\
\hline 1 & Baiq Marlian & Selatan SDN 2 Darmaji \\
\hline 2 & Mawardi & Selatan SDN 2 Darmaji \\
\hline 3 & Lalu Abdul Hamid & Depan KUD Desa Darmaji \\
\hline 4 & Lalu Syarifudin & Depan TK Dahlia \\
\hline 5 & Lalu Sudarja & Depan SDN 1 Darmaji \\
\hline
\end{tabular}




\section{Monitoring Penerapan Teknologi}

Penerapan LRB yang terdapat di 3 lokasi percontohan menghasilkan pupuk kompos. Kompos tersebut merupakan hasil proses pembusukan sampah organik yang telah dimasukkan ke dalam lubang resapan. Selain itu, ketika musim hujan LRB telah berfungsi dalam membantu meresapkan air genangan dengan cepat, sehingga genangan di sekitar pekarangan rumah masyarakat dapat diatasi.
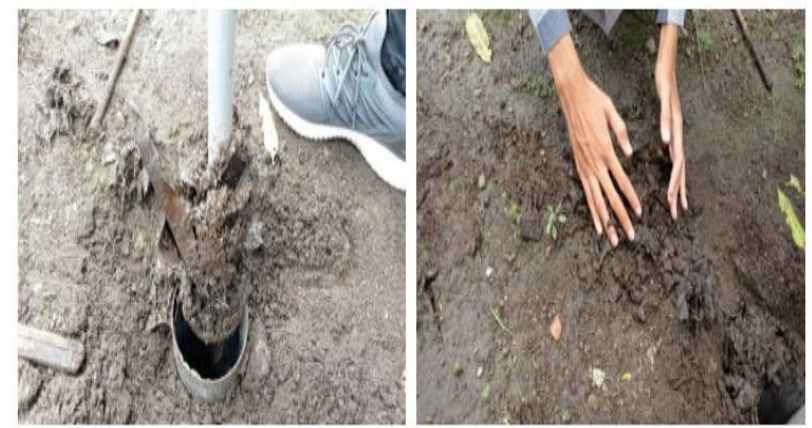

Gambar 7. Hasil pembusukan sampah organik dalam LRB. (setelah dimasukkan selama 3 minggu).
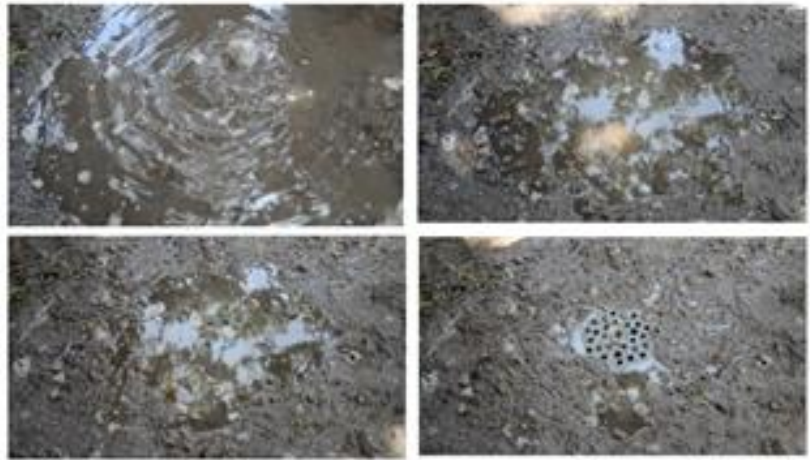

Gambar 8. Proses penyerapan air ketika terjadi genangan di sekitar LRB.
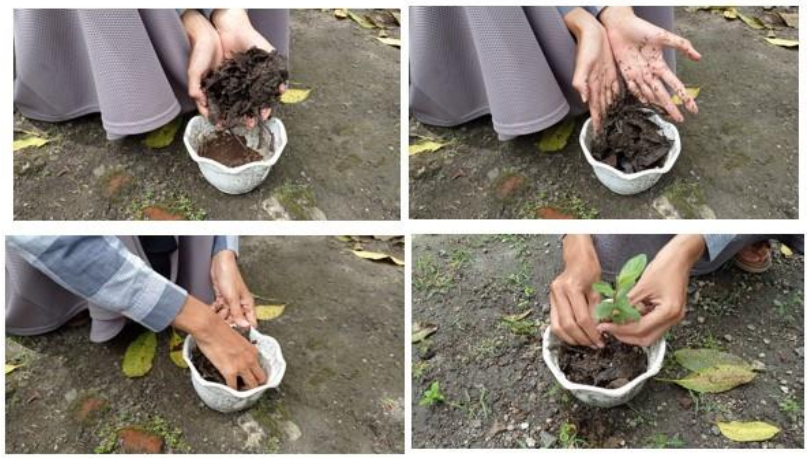

Gambar 9. Pemanfaatan pupuk kompos sebagai bahan pencampur tanah.

\section{Kesimpulan}

Berdasarkan kegiatan yang telah dilakukan, maka dapat ditarik beberapa kesimpulan sebagai berikut:

1. Lubang Resapan Biopori (LRB) dapat digunakan sebagai upaya peningkatan mutu kualitas lingkungan di Desa Darmaji.

2. Pemanfaatan LRB bukan hanya dapat meningkatkan mutu Lingkungan, namun dapat juga menunjang program Rumah Pangan Lestari dengan menghasilkan pupuk kompos untuk kegiatan pertanian.

Berdasarkan hasil sosialisasi didapatkan hasil bahwa masyarakat masih sangat awam dengan penerapan teknologi baru seperti LRB sehingga perlu dilakukan upaya pengenalan yang lebih intensif kepada masyarakat maupun pemerintah desa.

\section{Daftar Pustaka}

Griya.2008. Mengenal dan Memanfaatkan Lubang Biopori.(Online).(http://kumpulaninfo.com, diakses 11 Januari 2021)

R, Kamir Brata. 2009. Lubang Resapan Biopori untuk Mitigasi Banjir, Kekeringan dan Perbaikan.Prosiding Seminar Lubang Biopori (LBR) dapat Mengurangi Bahaya banjir di Gedung BPPT 2009. Jakarta. Anonim. 2008.

TIM IPB. 2007. Lubang Resapan Biopori (LBR). (Online). (http://biopori.com, diakses 11 Januari 2021).

Yohana, C., Griandini, D., Muzambeq, S. 2017. Penerapan Pembuatan Teknik Lubang Pembuatan Teknik Lubang Biopori Resapan Sebagai Upaya Pengendali Banjir. Jurnal Pemberdayaan Masyarakat Madani. 1(2):196-308.

https://doi.org/10.21009/JPMM.001.2.10 